\title{
Early Stages of Microstructure and Texture Evolution during Beta Annealing of Ti-6Al-4V
}

\begin{abstract}
A.L. PILCHAK, G.A. SARGENT, and S.L. SEMIATIN
The early stages of microstructure evolution during annealing of Ti-6Al-4V in the beta phase field were established. For this purpose, a series of short-time heat treatments was performed using sheet samples that had a noticeable degree of alpha-phase microtexture in the as-received condition. Reconstruction of the beta-grain structure from electron-backscatter-diffraction measurements of the room-temperature alpha-phase texture revealed that microstructure evolution at short times was controlled not by general grain growth, but rather by nucleation-and-growth events analogous to discontinuous recrystallization. The nuclei comprised a small subset of beta grains that were highly misoriented relative to those comprising the principal texture component of the beta matrix. From a quantitative standpoint, the transformation kinetics were characterized by an Avrami exponent of approximately unity, thus suggestive of metadynamic recrystallization. The recrystallization process led to the weakening and eventual elimination of the initial beta texture through the growth of a population of highly misoriented grains.
\end{abstract}

https://doi.org/10.1007/s11661-017-4444-8

(C) The Minerals, Metals \& Materials Society and ASM International 2017

\section{INTRODUCTION}

BETA annealing is often used for alpha/beta titanium alloys to develop a transformed microstructure for fracture-critical aerospace applications. Beta annealing is also applied as a solution treatment for beta and near-beta alloys prior to aging in the alpha/beta phase field. In both cases, the control of the beta grain size, resulting alpha colony size, and texture can be very important to mechanical properties.

Because of the industrial importance of the workhorse alpha/beta titanium alloy, Ti-6Al-4V, numerous investigations of its beta-grain-growth characteristics have been performed. Some of these efforts have indicated a parabolic behavior which characterizes classical normal grain growth; i.e., $\mathrm{d}^{\mathrm{n}} \sim \mathrm{t}$, in which $\mathrm{d}$ denotes the average grain size, $\mathrm{t}$ is time, and $\mathrm{n}$ is the grain-growth exponent. ${ }^{[1]}$ On the other hand, a number of measurements have shown substantial deviations from parabolic behavior. ${ }^{[2-6]}$ Specifically, periods of rapid and slow growth have been observed during both isothermal heat treatments and processes involving continuous heating. Furthermore, grain-growth kinetics have been found to

\footnotetext{
A.L. PILCHAK and S.L. SEMIATIN are with the Air Force Research Laboratory, Materials and Manufacturing Directorate, AFRL/RXCM, Wright-Patterson Air Force Base, OH 45433. Contact e-mail: adam.pilchak.1@us.af.mil G.A.SARGENT is a consultant for UES, Inc., 4401 Dayton-Xenia Road, Dayton, OH 45432.

Manuscript submitted May 15, 2017.

Article published online December 24, 2017
}

vary quite noticeably in different lots of Ti-6Al-4V with nominally identical composition and initial microstructure, but different initial textures. These observations have been rationalized on the basis of the evolution of texture during grain growth. Such texture-controlled grain growth is a result of the anisotropy in energy and mobility of beta grain boundaries, whose effects have been quantified using deterministic, Monte-Carlo, and phase-field simulation methods. ${ }^{[7-11]}$

Phenomenological measurements and modeling research on beta grain growth have been complemented by investigations which have shed light on the relation between the beta-phase texture developed during subtransus processing and that which evolves during annealing in the single-phase beta field. For example, Moustahfid, Divinski, and their coworkers ${ }^{[12,13]}$ were perhaps the first to demonstrate that the beta-phase texture developed during beta annealing contains components that were present during subtransus processing. Thus, it was concluded that the beta grew from pre-existing regions of this phase. However, their results also revealed that certain texture components may grow preferentially during beta annealing. For rolled sheet of Ti-6Al-4V, for example, the data indicated that the beta phase tended to consist of $\{001\}\langle 110\rangle$ and $\{111\}\langle 11 \overline{2}\rangle$ components after low temperature rolling, but preferential growth in the beta field resulted in a texture dominated by the latter component.

The early insights of Moustahfid, Divinski et al. ${ }^{[12,13]}$ were corroborated by Bhattacharyya et al. ${ }^{[14]}$ and Obasi et $a l^{[15]}$ who relied on in-situ, neutron-diffraction 
observations to show that the beta grains that grew during beta annealing did indeed originate from the small amount of this phase present in the as-received alpha/beta processed material.

Despite the excellent work of past investigators, the current picture of the mechanisms underlying the evolution of the beta microstructure is still incomplete. A fundamental understanding of such mechanisms would aid in the prediction of beta grain size as a function of the magnitude and uniformity of prior alpha/beta hot work, the propensity for abnormal grain growth during beta annealing, and the characteristics of beta grain boundaries that are needed for mesoscale simulations of grain growth. As a first step in meeting such needs, the present work was undertaken. Its main objective was to provide a detailed picture of the mechanism(s) that underlie the early stages of beta-grain formation and growth during beta annealing of subtransus-processed alpha/beta titanium alloys. A secondary objective was to determine if thermomechanical processes which give rise to regions of microtexture (or so-called macrozones), in which all of the equiaxed-alpha particles have the same or nearly the same orientation, ${ }^{[1-18]}$ also exhibit beta-phase microtexture and hence larger effective initial beta grain sizes upon reaching the single phase field. For these purposes, commercially-rolled sheet samples of Ti-6Al-4V were subjected to supertransus heat treatments of various durations and cooled rapidly. Electron-backscatter diffraction (EBSD) was then employed to determine macro/micro- textures and associated features of microstructure evolution.

\section{MATERIAL AND PROCEDURES}

\section{A. Material}

The material used in this investigation was Ti-6Al-4V. It came from the same lot of material used in a previous effort focused on alpha-variant selection following beta annealing. ${ }^{[19]}$ It had a measured composition (in weight percent) of 6.08 aluminum, 3.89 vanadium, 0.15 oxygen, 0.19 iron, 0.008 nitrogen, 0.014 carbon, 0.0044 hydrogen, with the balance being titanium. It was received as $1.5-\mathrm{mm}$ thick sheet in the subtransus-hot-rolled-and-surface-ground condition. The beta-transus temperature (at which alpha + beta $\rightarrow$ beta) was $1268 \mathrm{~K}\left(995^{\circ} \mathrm{C}\right)$.

The microstructure of the as-received sheet material consisted of primary-alpha particles and a small fraction $(<10 \mathrm{pct})$ of fine beta grains (Figure 1a). As characterized by $(0001)_{\alpha}$ and $(10 \overline{1} 0)_{\alpha}$ pole figures, the alpha-phase texture was moderately strong; it comprised primarily a component along the transverse direction (TD) and weaker components lying along the rolling direction (RD) and a direction lying between the normal direction (ND) and RD (Figure 1b). In these and subsequent pole figures, the RD and TD are at the 12 and 9 o'clock positions, respectively, and the ND is located at the center. Furthermore, texture intensities are reported in times-random units in all cases.

By and large, the beta-phase texture of the as-received sheet, as exemplified by $(001)_{\beta}$ and $(110)_{\beta}$ pole figures (Figure 1b), consisted of typical bcc rolling texture components $\{001\}\langle 001\rangle$ (at $\sim 8.5 \times$ random in the orientation distribution function or ODF) and an additional split component between the ND and RD characterized by the $\{111\}\langle 11 \overline{2}\rangle$ ideal orientation at $\sim 12 \times$ random in the ODF. Although the Burgers orientation relation was eliminated by hot rolling below the beta-transus temperature, some of the components of this texture, although weaker, mirrored those in the alpha-phase texture.

The degree of spatial correlation of the texture components was revealed in inverse-pole-figure (ipf) maps for the two phases. The alpha phase exhibited a noticeable degree of microtexture (Figures 2(a) and (b)). Despite the limited amount of retained beta, EBSD measurements using a very fine step size $(0.5 \mu \mathrm{m})$ over a large scan area revealed a range of beta orientations present at dimensions much smaller than the size of the alpha-phase microtextured regions (Figure 2(c)). In most cases, adjacent packets of underlying beta-phase were highly misoriented with respect to one another.

\section{B. Experimental Procedures}

To quantify the evolution of the microstructure and texture of the beta phase during annealing above the transus, dogbone-shape test samples (Figure 3) were electric-discharge machined (EDM'ed) along the RD of the as-received Ti-6Al-4V sheet and subjected to a variety of heat treatments. For this purpose, the reduced section, fillets, and a portion of the shoulder regions of each sample were heated using an indirect-resistance furnace. To avoid oxidation, each test specimen was enclosed in a quartz tube through which dried argon was passed. The heating cycle (Figure 4) consisted of raising the sample temperature to $1073 \mathrm{~K}\left(800{ }^{\circ} \mathrm{C}\right)$ at a rate of $\sim 235 \mathrm{~K} / \mathrm{min}$ $\left(\sim 235^{\circ} \mathrm{C} / \mathrm{min}\right)$, then heating to $1233 \mathrm{~K}\left(960{ }^{\circ} \mathrm{C}\right)$ at a rate of $\sim 80 \mathrm{~K} / \mathrm{min}\left(\sim 80^{\circ} \mathrm{C} / \mathrm{min}\right)$ holding for 3 minutes to dissolve most of the primary alpha and to homogenize the composition of the beta phase, and then heating at a rate of $85 \mathrm{~K} / \mathrm{min}\left(85^{\circ} \mathrm{C} / \mathrm{min}\right)$ to a temperature of $1285 \pm 2 \mathrm{~K}$ $\left(1012 \pm 2{ }^{\circ} \mathrm{C}\right)$; i.e., $\sim 15 \mathrm{~K}\left(\sim 15^{\circ} \mathrm{C}\right)$ above the beta-transus temperature. Upon reaching the peak temperature, each sample was held for a pre-specified time followed by controlled cooling at a rate of approximately $155 \mathrm{~K} / \mathrm{min}$ $\left(155^{\circ} \mathrm{C} / \mathrm{min}\right)$. This resulted in diffusional decomposition of the beta phase and thereby produced moderately-coarse lamellar alpha. The thermal excursion experienced by each sample was independently measured with a thermocouple to deduce the time between that when the material reached the beta-transus until it cooled to $1227 \mathrm{~K}\left(954^{\circ} \mathrm{C}\right)$ at which there was sufficient undercooling to nucleate alpha-phase to pin any mobile beta grain boundaries. This resulted in effective soak times ranging from 0 to 12.5 minutes which provided a series of snapshots of microstructure evolution.

Following heat treatment, each sample was mounted, ground to the plan-view mid-plane, mechanically polished, and final electropolished prior to insertion into an XL30 field-emission-gun, scanning electron microscope (FEI, Hillsboro, OR) for determination of the texture of 

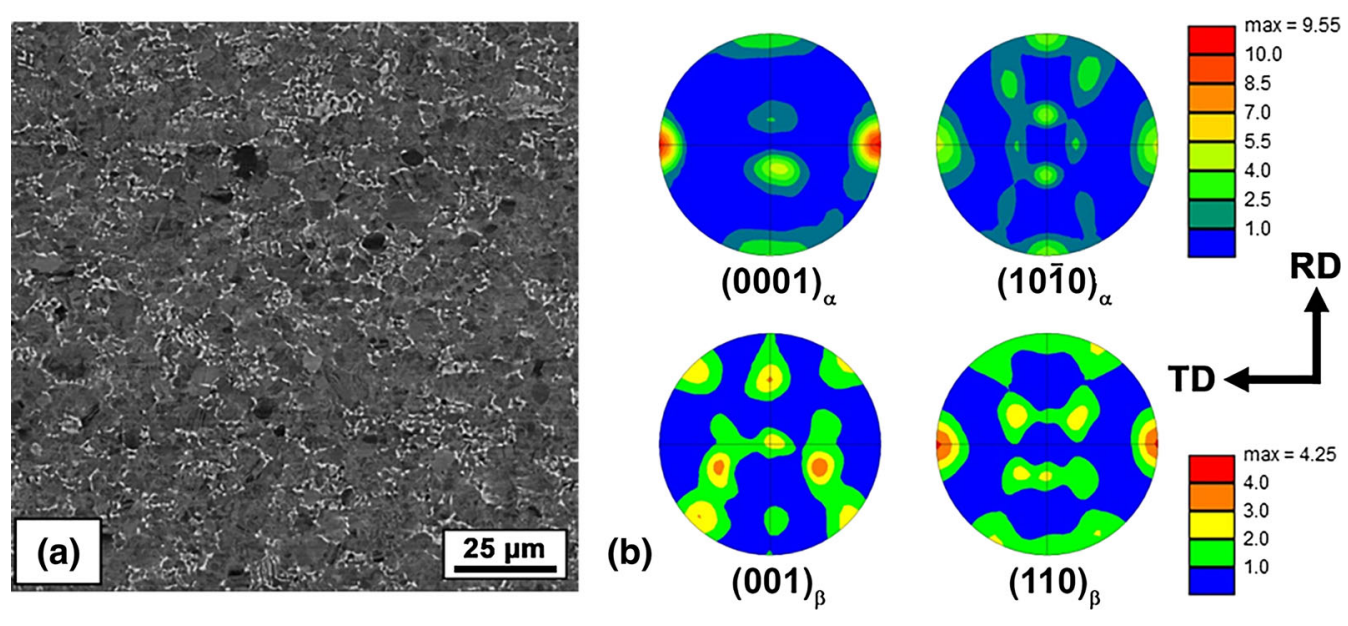

Fig. 1-Microstructure and texture of the as-received Ti-6Al-4V sheet material: $(a)$ Backscattered-electron (BSE) image (alpha is the darker phase, and beta/transformed beta is lighter) and $(b)(0001)_{\alpha},(10 \overline{1} 0)_{\alpha},(001)_{\beta}$, and $(110)_{\beta}$ pole figures.
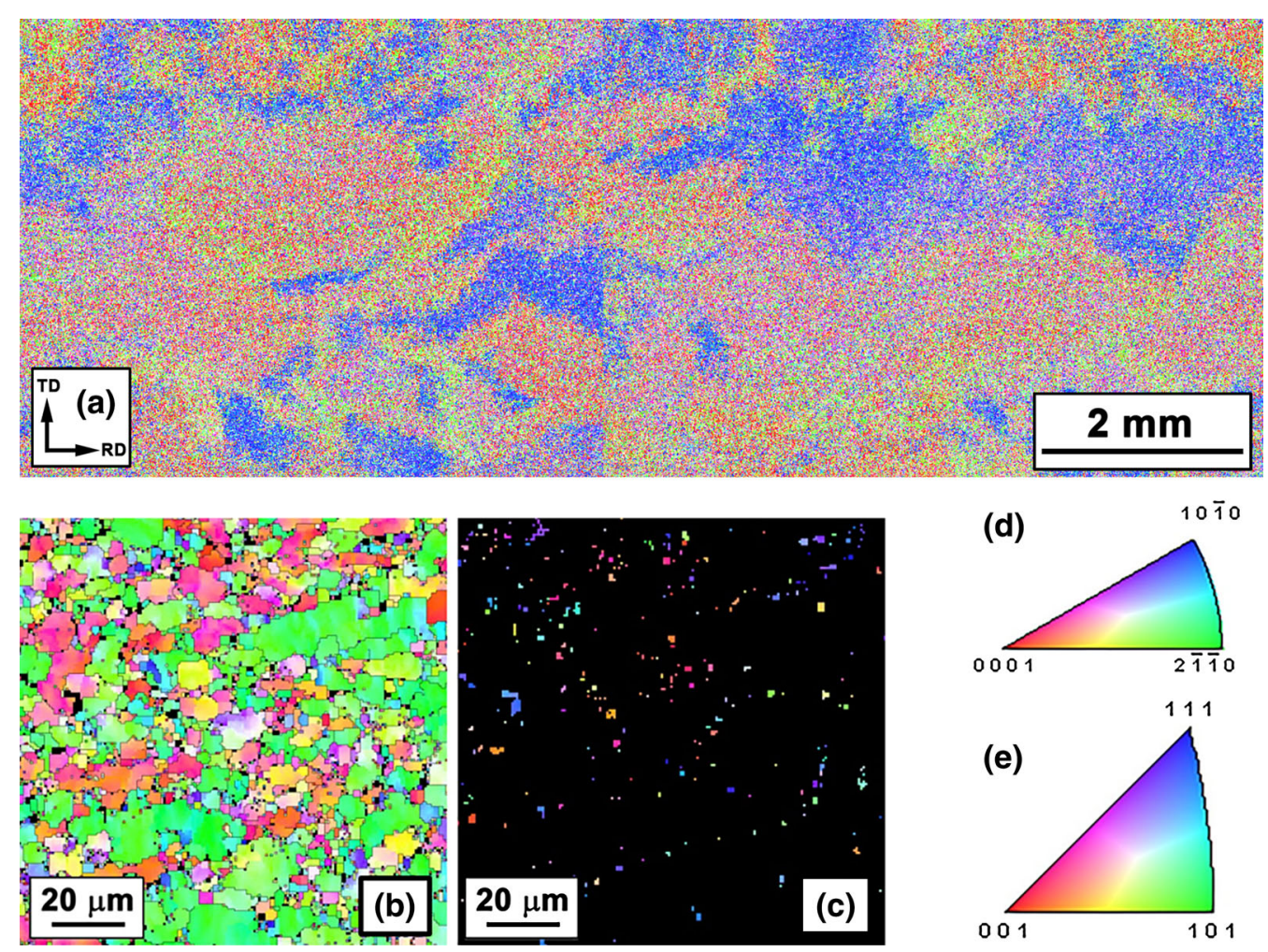

Fig. 2-EBSD inverse-pole-figure maps for $(a)$ rolling and $(b, c)$ sheet normal directions for the $(\mathrm{a}, \mathrm{b})$ alpha and (c) beta phases. Crystallographic orientations throughout this manuscript are colored according to the standard triangles for the $(d)$ alpha and $(e)$ beta phases.

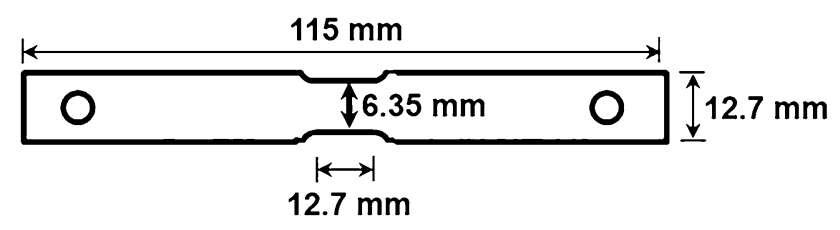

Fig. 3-Test-sample geometry.

the alpha phase. For this purpose, the microscope was operated at $20 \mathrm{kV}$ and spot size 5 with a final aperture diameter of $100 \mu \mathrm{m}$, thereby producing a probe current of $49 \mathrm{nA}$. The stage was tilted $70 \mathrm{deg}$ for all measurements. Local alpha-phase Kikuchi patterns produced as a result of EBSD were collected over the entire gauge section of the sample at a rate of $\sim 210$ frames per second using a step size of $4 \mu \mathrm{m}$ and were analyzed with EDAX/TSL OIM ${ }^{\mathrm{TM}}$ software (EDAX Corp., Mahwah, NJ). The large scan area necessitated both beam and stage control and subsequent stitching of the resulting data. ${ }^{[20,21]}$

Because of the limited volume fraction of the beta phase in Ti-6Al-4V at room temperature $(\sim 5 \mathrm{pct})$, only 


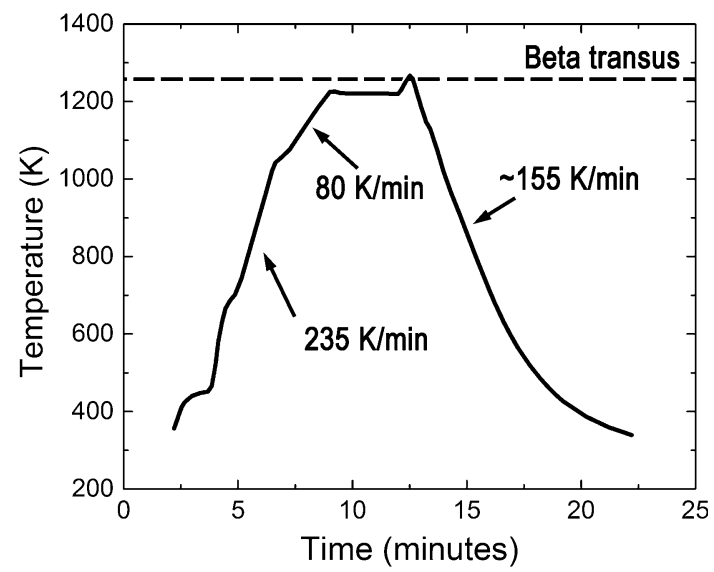

Fig. 4 -Schematic illustration of the heating and cooling profile used to beta-anneal Ti-6Al-4V samples in the current work.

limited EBSD results were obtained for this phase. Because the orientations of the alpha and beta phases in the as-received (alpha/beta processed) material did not follow the Burgers relation, and hence could not be reconstructed from measured alpha-phase data, the beta texture in this condition was determined directly from approximately 16,000 beta-phase EBSD data points taken from an area identical in size to that used in the reconstruction method, i.e., $\sim 6 \mathrm{~mm} \times 12 \mathrm{~mm}$, which was covered using a $2 \mu \mathrm{m}$ step size. Following beta annealing, an alternate method was applied to determine the orientations and hence texture of the underlying beta subgrains/grains for the beta-annealed samples from the measurements for the alpha phase. This method was similar to that developed by Humbert et al..$^{[22,23]}$ and Glavicic et al. ${ }^{[24,25]}$ For the present technique, however, the quaternion parameterization of orientation space was used in conjunction with average alpha-colony orientations (as described by Pilchak and Williams ${ }^{[26]}$ ) in contrast to the pixel-by-pixel methods employed by the previous researchers. This enabled complete reconstruction of the beta grains in an area measuring $\sim 6 \mathrm{~mm} \times 12 \mathrm{~mm}$ (at full resolution) in several minutes. The reconstruction algorithm used a tolerance of $2 \mathrm{deg}$ when comparing the angle/axis pairs of observed colonies to the theoretical operators for two alpha colonies exhibiting the Burgers orientation relationship with the same parent beta grain. Moreover, a minimum of 4 unique alpha variants were considered when identifying the prior beta grain orientation in order to overcome the deficiency in reconstruction noted by Cayron $^{[27]}$ associated with a $\{111\}$ mirror plane that gives rise to an alternate, twin-related prior beta grain orientation. This is a subtle but important point as a minority texture component identified later is indeed twin related to the principal texture and so extreme care was taken to ensure this was not an artifact of the reconstruction process.

Data analysis consisted of segmenting the reconstructed beta grains with a $15 \mathrm{deg}$ misorientation tolerance to separate the populations of "recrystallized" and "unrecrystallized" grains so that average size and volume fraction of each could be determined. Furthermore, a minimum size threshold of 100 pixels $(\sim 30 \mu \mathrm{m}$ diameter) was imposed for recrystallized grains based on backscattered electron imaging observations. Pole figures and ODFs with orthotropic sample symmetry were calculated using the discrete binning method on a $2 \mathrm{deg}$ resolution grid in orientation space to overcome artifacts introduced to the spherical harmonic representation by the strong rotated cube texture. Discrete pole figures and ODF sections, which more clearly represent the minority texture components in the presence of a strongly dominant one, were also calculated. Composite pole figures and ODFs were then created by merging the discrete and contour plots.

\section{RESULTS}

The principal results from this investigation comprised characterization of the evolution of the microstructure and texture of the beta phase in samples annealed for various times above the beta-transus temperature.

\section{A. Microstructure Evolution}

Short-time beta annealing led to the development of relatively-small lamellar-alpha colonies as shown by backscattered electron imaging (Figure 5a). Sporadic observations of equiaxed beta grains surrounded by grain-boundary alpha (whereas the majority of the microstructure did not have grain boundary alpha) also suggested that the chosen heat treatments had been successful in limiting the average beta grain size to less than $\sim 50 \mu \mathrm{m}$ for the shortest heat-treatment times (Figure 5b).

More-detailed insight into the evolution of the beta-phase microstructure during beta annealing was discerned using sheet-normal-direction ipf maps (such as those shown in Figures 6 and 7) which had been reconstructed from the measured alpha phase EBSD data. For example, the overall map for an entire scan (Figure 6) indicated the presence of a single texture component which can be considered as a large beta grain with a relatively-constant orientation as indicated by the red color. The red color was consistent with the $\{001\}\langle 110\rangle$ bcc rolling texture in the as-received sheet (Figure 1b). In addition, a number of small, grain-like, features were noticed within the matrix. Many of these grains were blue, yellow or purple in color and represented both ideal texture components (viz. $\{111\}\langle 11 \overline{2}\rangle$ ) and other highly-misoriented orientations.

A closer examination of the ipf data (e.g., Figure 7) indicated that the red matrix actually comprised small gradations in color indicating the presence of an aggregate of subgrains. Such gradations likely mirrored the small orientation gradients that are typically associated with microtextured regions of alpha-phase following hot working. The boundaries between the beta subgrains and the small grains of other colors were also 

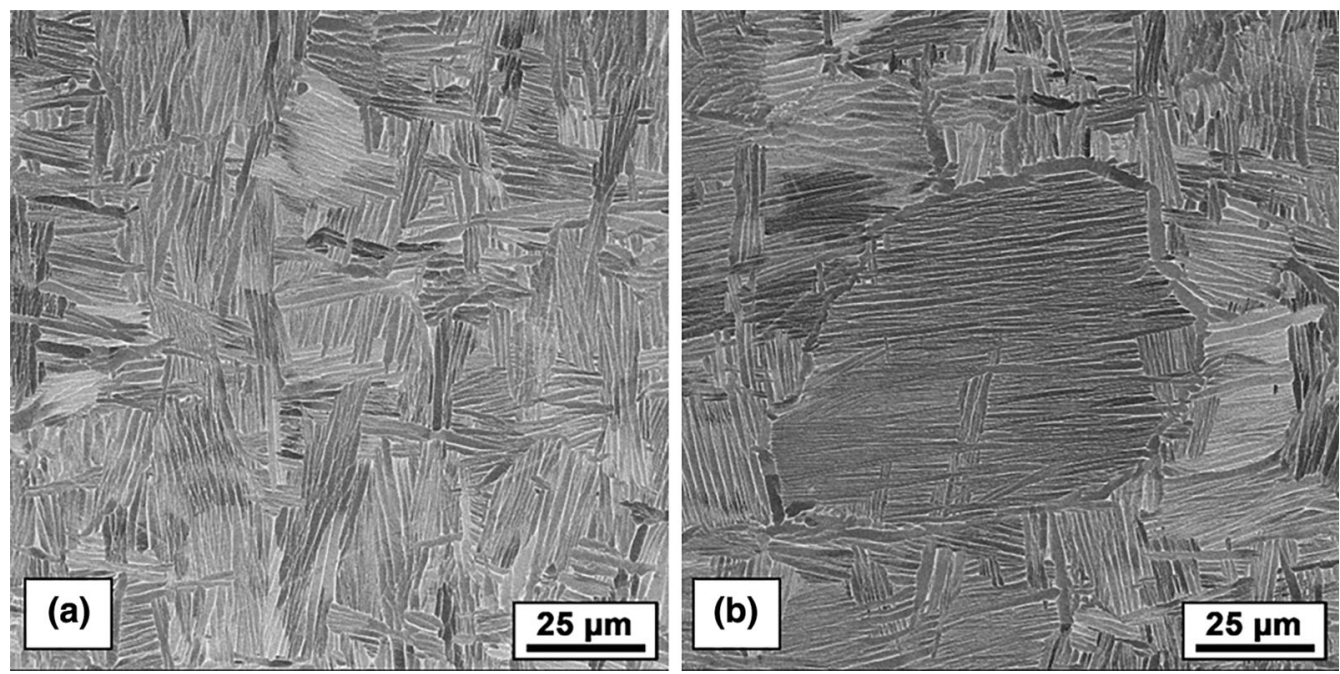

Fig. 5-Backscattered electron micrographs of the $(a)$ transformed-beta matrix and $(b)$ a representative "recrystallized" beta grain.

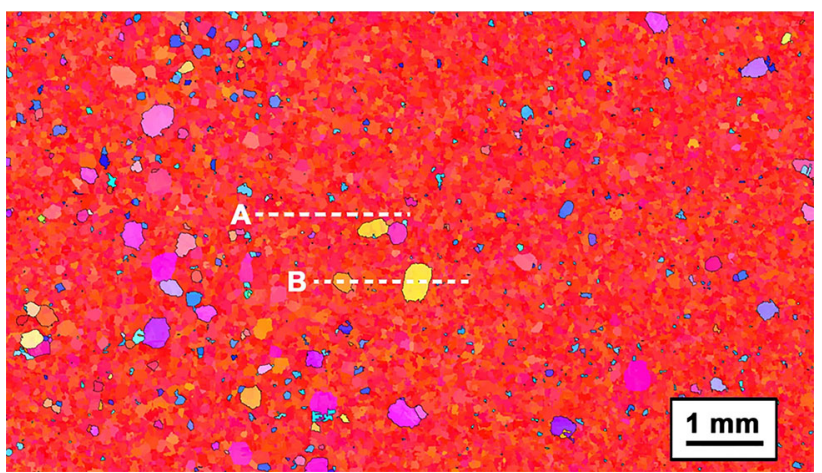

Fig. 6-Normal direction inverse pole figure map depicting beta-phase microstructure evolution in a Ti-6Al-4V sample annealed above the beta transus for $31.5 \mathrm{~s}$.

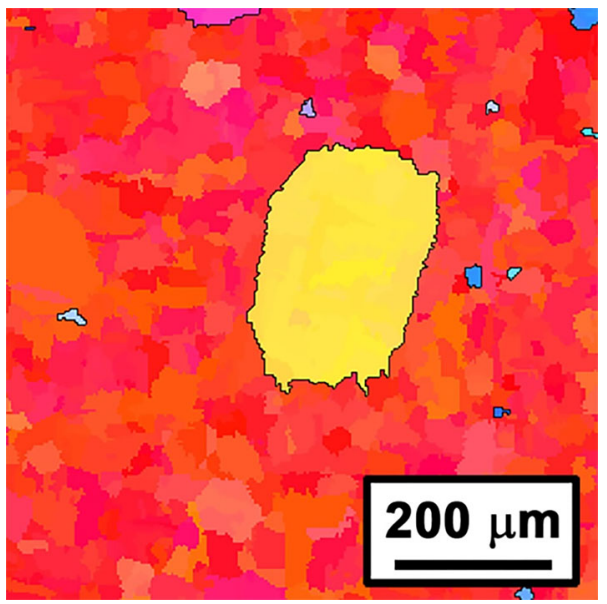

Fig. 7-Normal direction inverse pole figure map illustrating the nature of subgrains during beta-phase microstructure evolution in a Ti-6Al-4V sample annealed above the beta transus for $31.5 \mathrm{~s}$.

quite distinct, but somewhat irregular in shape due in part to the $4 \mu \mathrm{m}$ EBSD resolution and beta-grain reconstruction process. The almost 100 pet volume fraction of $\{001\}\langle 110\rangle$-oriented grains at the shortest annealing times is noteworthy considering that it was not the strongest texture component in the as-received material. This implies that this orientation either grew epitaxially from existing beta phase at a faster rate than the other orientations, preferentially consumed other beta orientations during the brief subtransus hold, or some combination of both. This observation warrants further investigation, but is outside the scope of the present effort.

EBSD traverses confirmed the nature of the subgrain/grain boundaries in the ipf maps. The results of two representative traverses (indicated by the broken lines in Figure 6) are shown in Figure 8. Traverse A through a region containing all red grains (Figure 6) exhibited misorientations greater than 3 deg but less than $15 \mathrm{deg}$ across the various boundaries. Such observations were indicative of a subgrain structure in the red matrix. By contrast, traverse B (which passes through the orange and yellow grains in Figure 6) showed misorientations up to $30 \mathrm{deg}$ across its boundary with the red matrix phase (Figure 8). Thus, entities such as these were indeed grains surrounded by high-angle boundaries. Traces through other "recrystallized" grains approached angles as high as $60 \mathrm{deg}$. The traverse-B results also revealed that the misorientations within the grain itself were very low and within the resolution of EBSD measurements and subsequent reconstruction $(\leq 2 \mathrm{deg})$. Therefore, the grains were essentially strain-free.

Additional EBSD ipf maps (Figure 9) revealed the various stages of microstructure evolution. The maps detail the nucleation and growth of two populations of grains. The first was a collection of highly misoriented subgrains that were still a part of the principal rotated cube $\{001\}\langle 110\rangle$ texture component while the second were initially small grains of orientations different from the (red) matrix orientation. The number of grains per unit volume remained relatively constant during the early stages of growth. Eventually, the entire red matrix was consumed by such grains. The highly-misoriented grains 

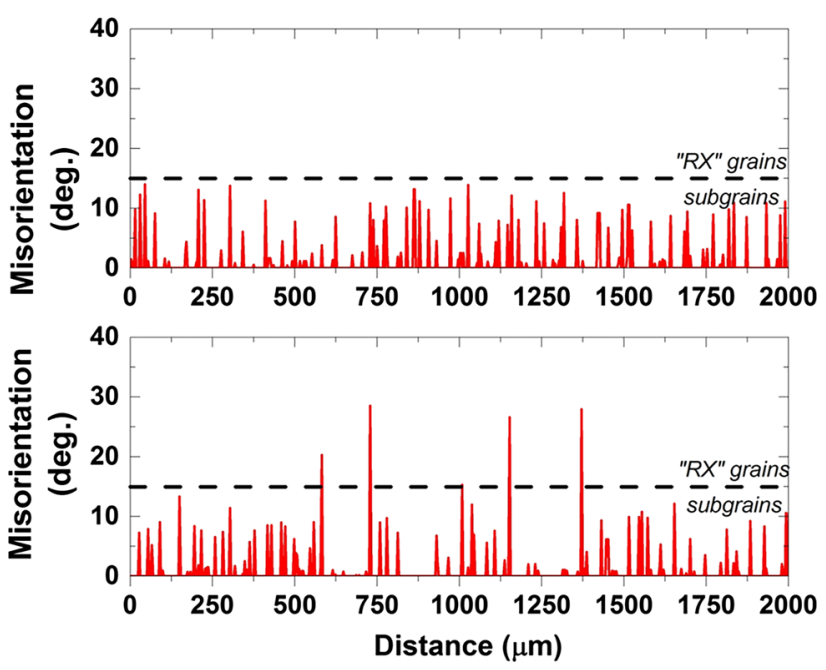

Fig. 8-Point-to-point EBSD misorientation profiles for traverses A (top) and B (bottom) indicated in Fig. 6.

and subgrains may be considered as the pre-existing nuclei in a nucleation-and-growth process. Thus, the present observations provide the first direct evidence that the early stages of beta annealing are in fact a form of discontinuous, metadynamic recrystallization, a possibility first suggested by Divinski et al. ${ }^{[13]}$ This conclusion is discussed further in Section IV.

\section{B. Texture Evolution}

Measurements of the crystallographic texture of the beta phase (determined via microstructure reconstructions based on alpha-phase data) shed further insight into the kinetics of the recrystallization process. The essential features were observed in beta-phase pole figures (Figures 10 and 11) and $\varphi_{2}=45 \mathrm{deg}$ sections of the ODF, Figure 12. For annealing times of approximately 50 seconds or less, the pole figures showed the predominant rotated cube texture, i.e., $\{001\}\langle 110\rangle$, although a very weak second texture component, $\{221\}\langle\overline{1} 14\rangle$ (related to the rotated cube through a rotation of $60 \mathrm{deg}$ about $\langle 111\rangle$ ), is evident as three spots in the discrete portion of the (001) pole figure. It is worth noting that this minority texture component was only identified through discrete pole figures. It was completely obfuscated in the spherical harmonic representation of texture and also in the discrete binning approach unless a small bin size, e.g., 2 deg, was used without subsequent application of a smoothing kernel. Following annealing for approximately 50 seconds, the intensity and sharpness of the rotated cube texture component decreased while there was a concomitant increase in the number of orientations at $\{221\}\langle\overline{1} 14\rangle$. The rotated cube component continues to broaden and decrease in intensity after heat treating for 100 seconds while the $\{221\}\langle\overline{1} 14\rangle$ spots weaken and become more diffuse. At yet further times of the order of 200 seconds, both the rotated cube and $\{221\}\langle\overline{1} 14\rangle$ orientations sharpen and strengthen slightly. Additionally, a number of new orientations were evident in the discrete plots at locations where the diffuse spot of the rotated cube were after 100 seconds of heat treatment before resharpening at 210 seconds. These new components strengthened during an additional time increment of approximately three minutes ( $\sim 400$ seconds total) effectively forming an annulus of considerably lower intensity that was $\sim 15 \mathrm{deg}$ wide centered $\sim 30 \mathrm{deg}$ from the initial ideal rotated cube orientation (which was still present at this time). The rotated cube was completely eliminated after an additional 5.8 minutes of heat treatment and was replaced entirely by the annulus and other texture components lying along the typical BCC rolling fibers having relatively low index planes including $\{112\}$, $\{113\}$, and $\{133\}$ lying in the plane of the sheet (Figure 13). The overall intensity of the final texture was much less than that of the original because the orientations were distributed over a much larger volume of orientation space following 750 seconds of beta annealing compared to the sharp rotated cube texture at short times. This sequence of texture evolution is reminiscent of classic texture-controlled grain growth giving further credence to metadynamic recrystallization as the operative mechanism since, in this mechanism, the nuclei are already present in the deformed structure and hence grow competitively with the matrix.

The pole-figure and ODF data were complemented by quantitative measurements of the texture components lying along the alpha fiber in the $\phi_{1}=0 \mathrm{deg}, \Phi$, $\phi_{2}=45 \mathrm{deg}$ section of the orientation distribution function (Figure 14). This plot shows one 'slice' through the ODF that depicts the evolution of orientations around a (001) pole in the plane of the sheet during beta annealing along the alpha-fiber. There is a large reduction in intensity during annealing and the replacement of the as-received texture component characterized by $\Phi=0 \mathrm{deg}$ by one with $\Phi \sim 30 \mathrm{deg}$. These results further reinforce the idea that the orientations in the tail of the rotated cube texture component, which have high energy and therefore high mobility, are the nuclei for metadynamic recrystallization.

\section{DISCUSSION}

The experimental observations of the evolution of the beta microstructure were interpreted in the context of conventional mechanisms of recrystallization. The two principal features of interest consisted of the overall transformation kinetics and the growth/migration rate of grains with high-angle boundaries.

\section{A. Transformation Kinetics}

The experimental observations demonstrated that microstructure evolution in subtransus-hot-rolled Ti-6Al-4V during the early-stages of heat treatment in the beta-phase field consisted of a nucleation-and-growth process. The nuclei comprised grains with mobile, high-angle boundaries relative to the majority of the beta matrix which consisted of fine subgrains possessing a sharp, rotated-cube texture, 

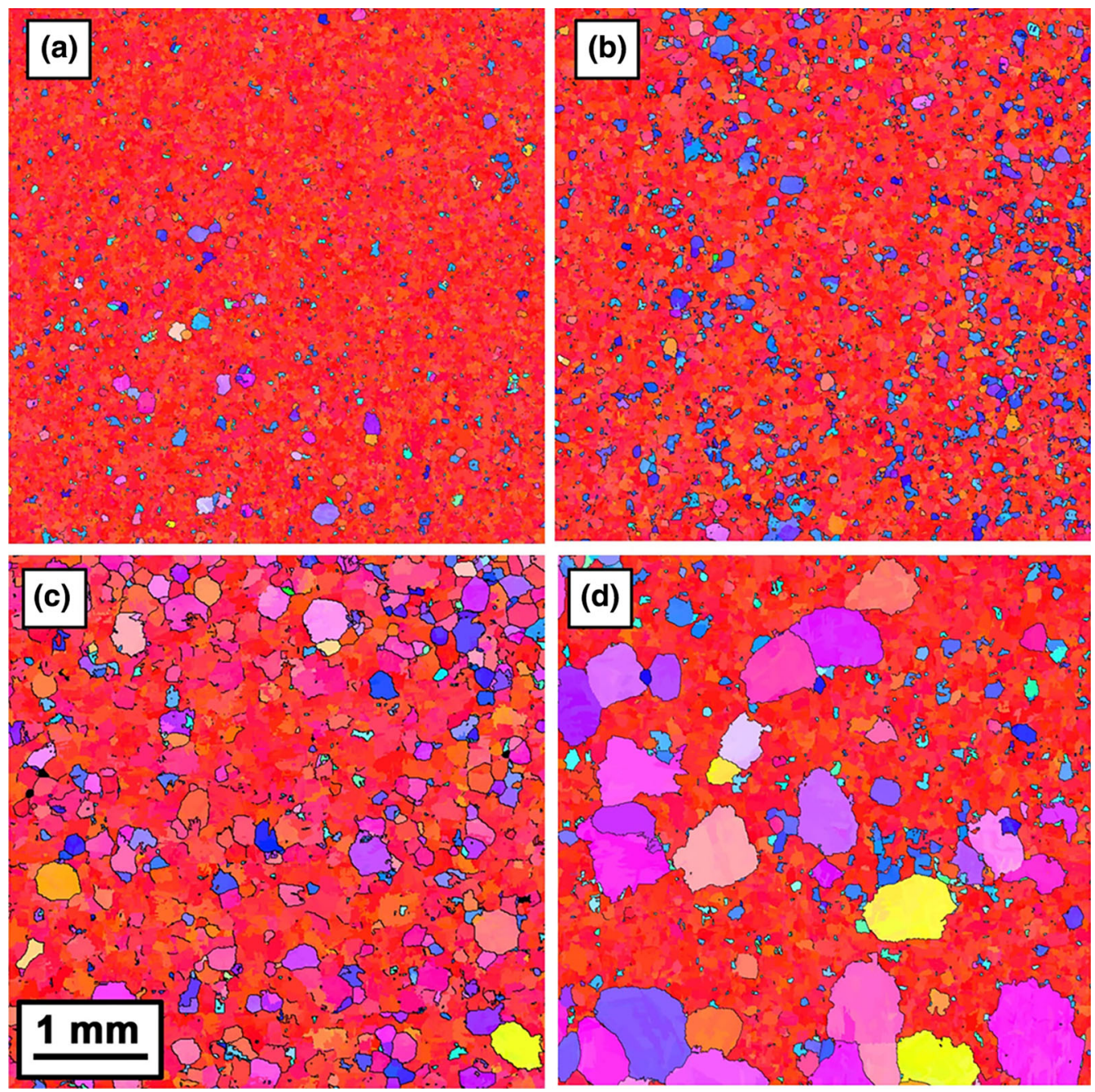

Fig. 9-Reconstructed beta-phase inverse pole figure maps for samples annealed above the beta transus for times of $(a) 10 \mathrm{~s},(b) 54 \mathrm{~s},(c) 100 \mathrm{~s}$, and (d) $210 \mathrm{~s}$.

(001) $\langle 110\rangle$. By contrast, the nuclei covered a much broader range of orientation space because the criterion for migration was related to the presence of high-angle boundaries with high energy. ${ }^{[7-9]}$ In particular, each $\langle 001\rangle$ component of the rotated cube can be taken as a principal orientation with a spherical Gaussian distribution surrounding it. Those orientations in the tail of the Gaussian represent the population of potentiallymobile grains. Thus, a large volume of orientation space satisfied the requirement for mobility. Because there was a significantly larger number of potential nuclei in orientation space compared to the main orientation, the overall intensity of the texture was significantly reduced upon annealing as an annular ring forms around the initial $\langle 001\rangle$ components, viz., Figure 10.

Because the nuclei appeared to have developed during prior hot working, the recrystallization process can be concluded to consist of discontinuous, metadynamic recrystallization. This hypothesis was verified by plotting the fractioned transformed $\mathrm{X}_{\mathrm{v}}$ (i.e., recrystallized) as a function of annealing time (Figure 15(a)). This plot showed that $\mathrm{X}_{\mathrm{v}}$ increased with time almost immediately, as expected. What appears to be a short incubation period between 0 and 30 seconds may be partially ascribed to the time required to dissolve the remnant alpha-phase particles and homogenize the partitioned solutes.*An example of non-dissolved alpha particles inhibiting growth is evident in Figure 16. The associated Avrami plot, viz., $\ln \left(\ln \left(1 /\left(1-\mathrm{X}_{\mathrm{v}}\right)\right)\right.$ vs $\ln (\mathrm{t})$, is shown in Figure 15(b). Although there is some scatter in this plot,

*Assuming a diffusivity $\mathrm{D}$ of $\sim 0.1 \mu \mathrm{m}^{2} / \mathrm{s}^{[28]}$ and an alpha-particle radius $\mathrm{r}$ of $2.5 \mu \mathrm{m}$, the dissolution/homogenization time would be of the order of $\mathrm{r}^{2} / 2 \mathrm{D} \sim 30$ seconds.

possibly due to an inhomogeneity of the initial microstructure/texture or inhomogeneous dissolution of primary alpha, the best straight-line fit of the slope yielded an Avrami exponent close to unity. Such a value has been reported a number of times for the recrystallization of hot-worked steels and nickel-base superalloys, ${ }^{[2-31]}$ and has been variously ascribed to dimensionality effects, ${ }^{[32,33]}$ in which the recrystallization 


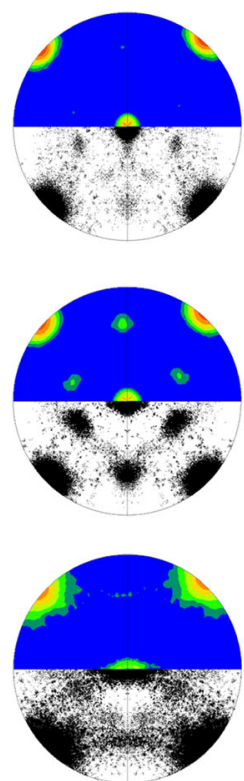

(001)

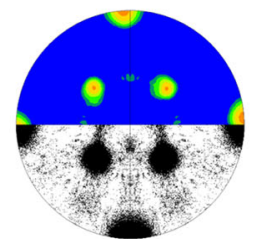

$10 \mathrm{~s}$

$30 x$

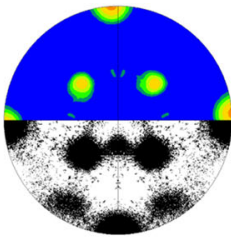

$54 \mathrm{~s}$

24x

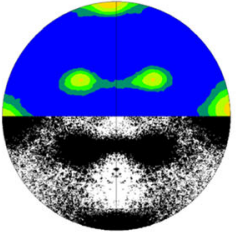

$100 \mathrm{~s}$

$17 x$

(011)
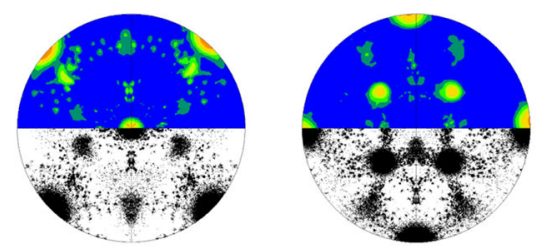

$210 \mathrm{~s}$

$20 x$

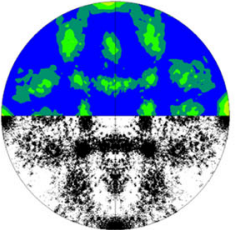

$398 \mathrm{~s}$

4.4x
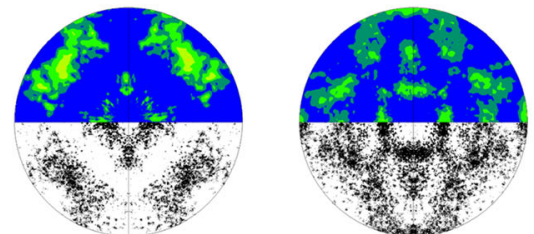

$750 \mathrm{~s}$

\section{$4.3 x$}

(001)

(011)

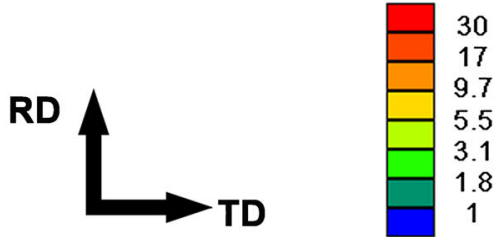

Fig. $10-(001)$ and (011) beta phase pole figures for samples annealed above the beta transus for the times indicated.
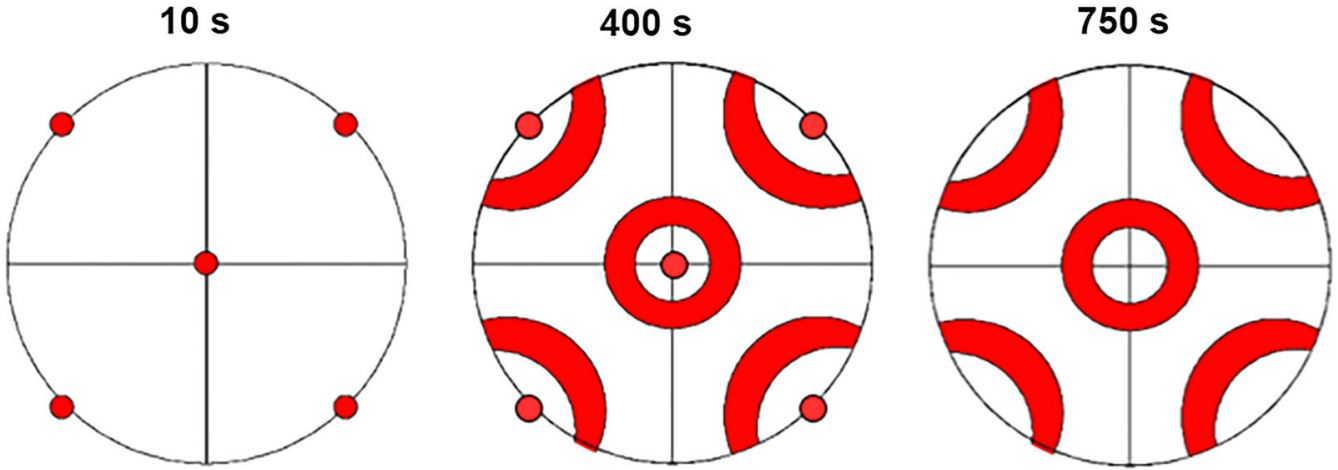

Fig. 11-Schematic illustration showing evolution of the strong rotated cube $\{001\}\langle 110\rangle$ texture component over $750 \mathrm{~s}$ of annealing in the beta phase field.

front grows in one-dimensional manner, or heterogeneous nucleation involving site-saturation behavior. ${ }^{[34]}$

\section{B. Rate of Grain-Boundary Migration}

The rate of growth of the nuclei with high-angle boundaries (HABs) was interpreted in the context of two simple models. The first, which tended to provide an upper bound, treated the growth of $\mathrm{HAB}$ grains into a matrix of subgrains and neglected grain impingement. The other, which tended to provide a lower bound, assumed that the growth of the grains led to impingement with other grains from the beginning of annealing; i.e., classical grain growth.

Upper-bound simulations were performed using an approach suggested by Humphreys. ${ }^{[35]}$ Denoting the radius, mobility, and boundary energy of the growing grain(s) as $\mathbf{R}, \mathbf{M}$, and $\gamma$, and the average radius and boundary energy of the subgrains as $\bar{R}$ and $\bar{\gamma}$, respectively, the rate of growth of the grain(s) is given by the following expression:

$$
\frac{\mathrm{dR}}{\mathrm{dt}}=\mathrm{M}\left(\frac{\bar{\gamma}}{\overline{\mathrm{R}}}-\frac{\gamma}{\mathrm{R}}\right)
$$



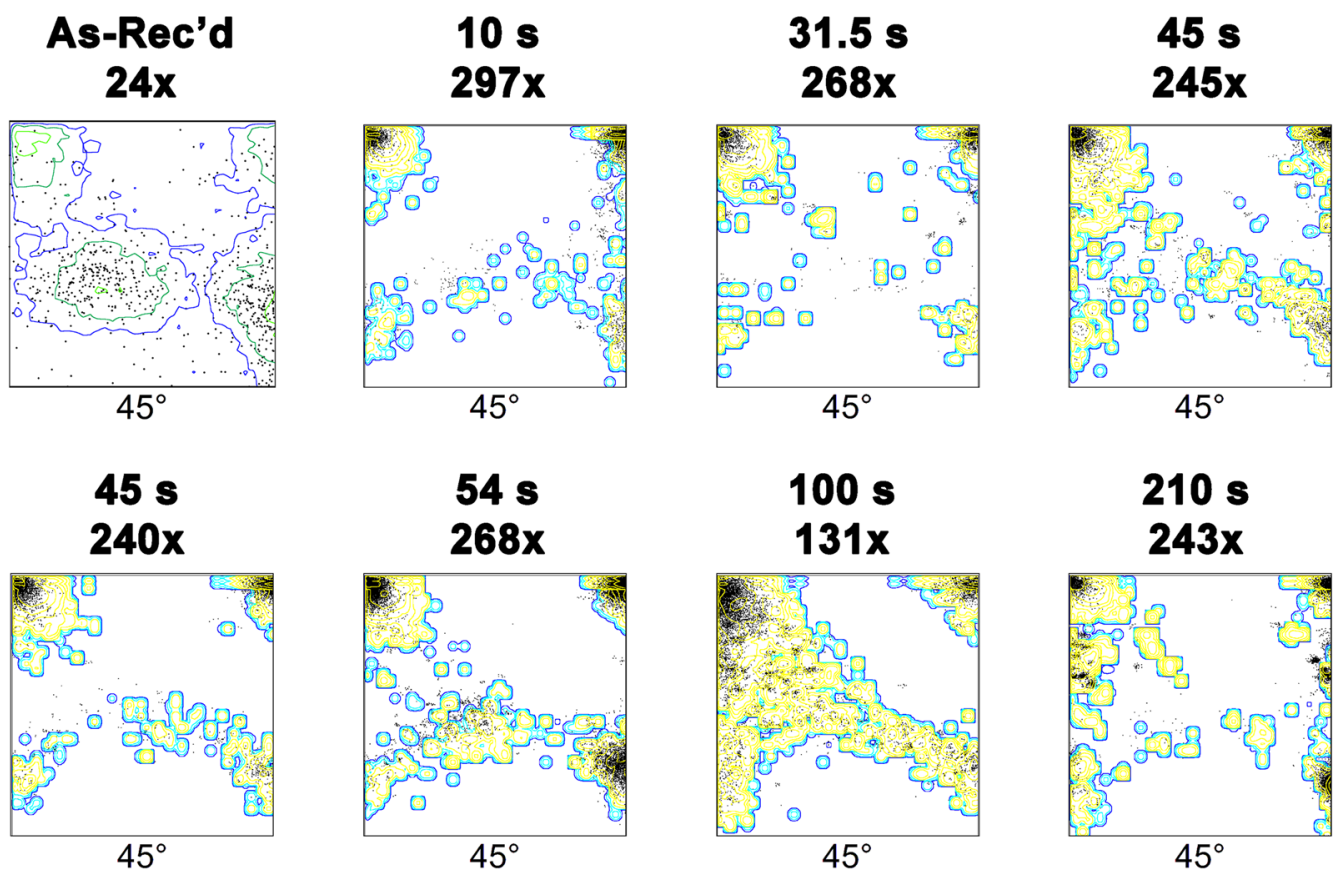

$54 \mathrm{~s}$

$100 \mathrm{~s}$

$210 \mathrm{~s}$ 268x

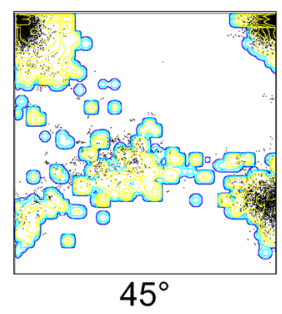

131x

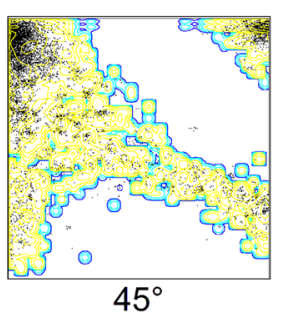
243x

$210 \mathrm{~s}$ 239x

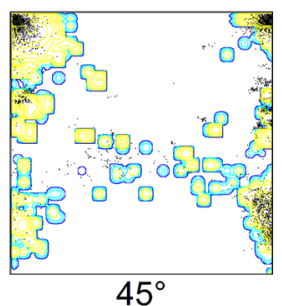

$398 \mathrm{~s}$

$34 \mathrm{x}$

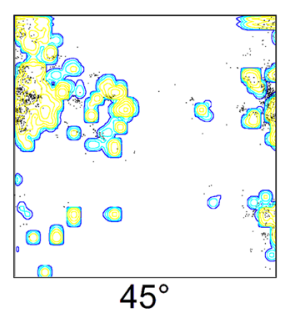

750 s $27 x$

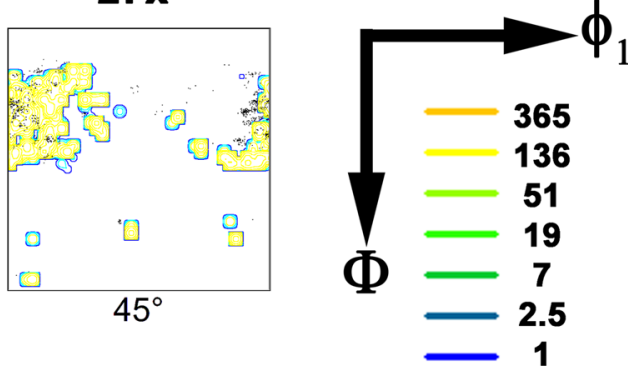

Fig. 12-Beta phase texture following annealing above the beta transus for the specified times represented as constant $\varphi_{2}=45$ deg sections of the orientation distribution function (maximum intensities reported above each section).

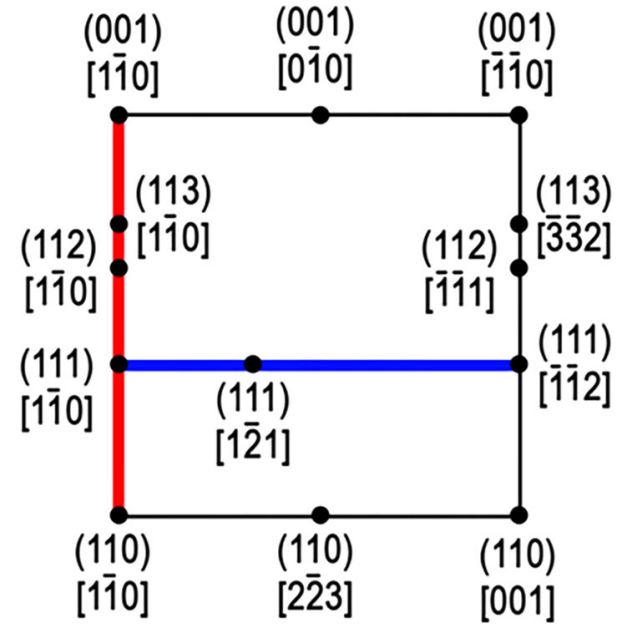

Fig. 13-Ideal orientations on the constant $\varphi_{2}=45$ deg section of the orientation distribution function. The alpha and gamma fibers are shown in red and blue, respectively.

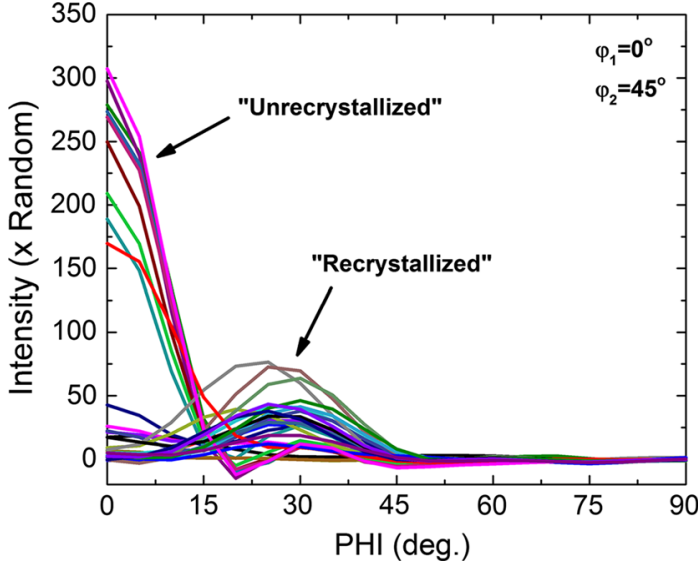

Fig. 14-Evolution of the beta-phase orientations along the alpha fiber (of the classic BCC rolling texture) during beta annealing of Ti-6Al-4V samples. 


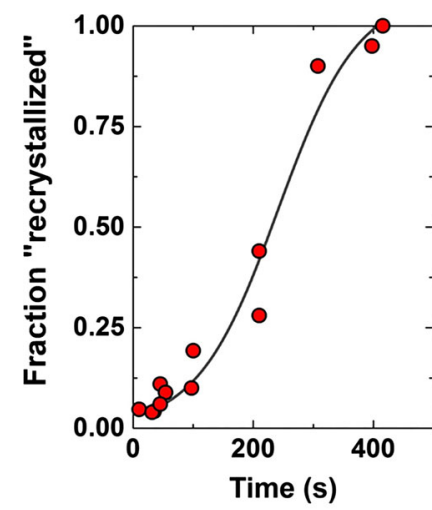

(a)

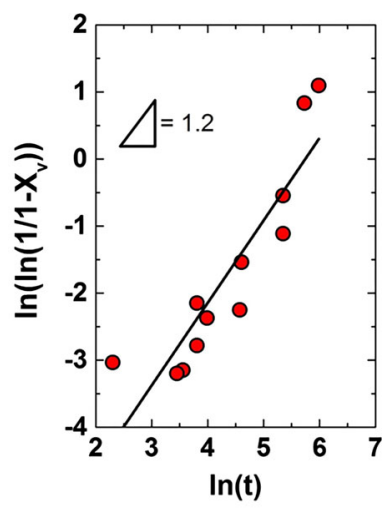

(b)
Fig. 15-Beta recrystallization kinetics: (a) Fraction recrystallized $\mathrm{X}_{\mathrm{V}}$ as a function of time $\mathrm{t}$ and $(b)$ corresponding Avrami plot.

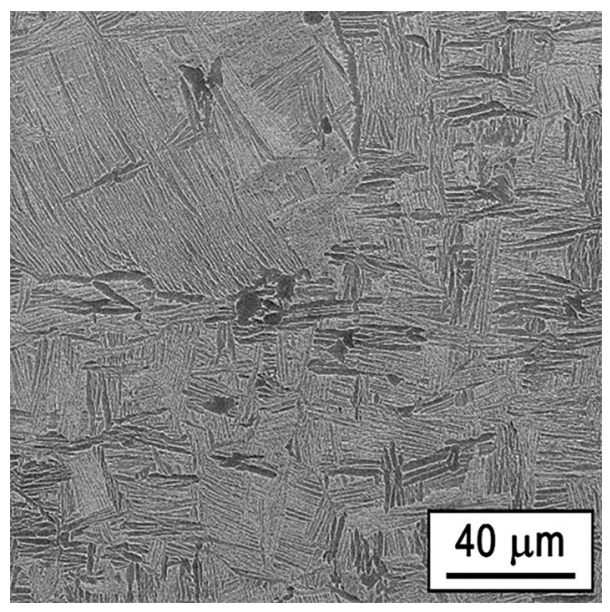

Fig. 16-Backscattered electron image showing remnant alpha particles following a 31.5 s soak above the beta transus.

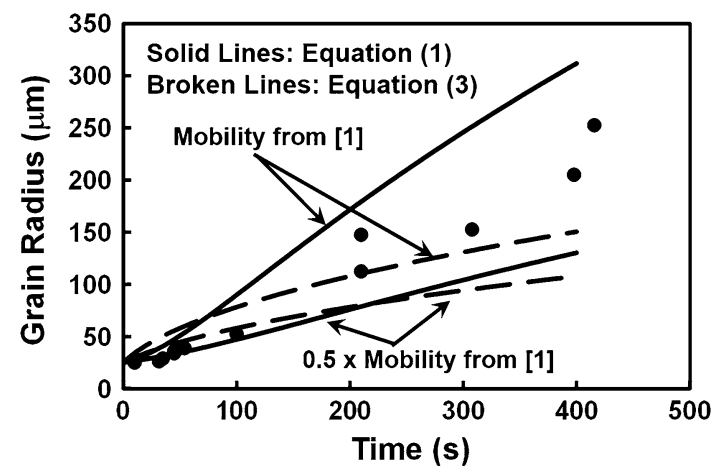

Fig. 17-Comparison of measurements and model predictions for the temporal evolution of the size of the beta grains having high-angle boundaries.

In Eq. [1], the value of the energy of the $\operatorname{HAB}(\gamma)$ was taken to be $1 \mathrm{~J} / \mathrm{m}^{2}$. The average boundary energy of the subgrains $(\bar{\gamma})$ was estimated from the Read-Shockley equation, ${ }^{[36]}$ i.e.,

$$
\bar{\gamma}=\gamma\left(\frac{\theta}{\theta_{\max }}\right)\left[1-\ln \left(\frac{\theta}{\theta_{\max }}\right)\right]
$$

Here, $\theta$ represents the average misorientation angle for the sub-boundaries ( $\sim 6 \mathrm{deg}$, per Figure 8(a)), and $\theta \max$ is the angle at which low-angle boundaries (LABs) become HABs, which was taken to be $15 \mathrm{deg}$ per the typical convention. With these vales for $\theta$ and $\theta \max , \bar{\gamma} / \gamma$ was estimated to be 0.77 . The average radius of the subgrains $\bar{R}$ was measured to be approximately $15 \mu \mathrm{m}$ for the shortest annealing time and increased by just under a factor of 2 after 400 seconds. The relatively slow subgrain growth rate was presumably because of the low energy and mobility of their boundaries as predicted by the Read-Shockley ${ }^{[36]}$ and Rollett-Holm ${ }^{[37]}$ equations, respectively.

The final parameter whose value was needed to apply Eq. [1] was the mobility $M$. As mentioned in the introduction, a number of measurements of grain growth during beta annealing, particularly for highly-deformed materials, have shown the importance of incorporating texture evolution in the development of a quantitative analysis. Texture-evolution effects (and not necessarily solute-drag per se), however, often give rise to an apparent grain-growth exponent whose value diverges noticeably from 2. Concurrent texture evolution can also confound the determination of the grain-boundary mobility M. An exception to most prior observations, the measurements of Semiatin et al. ${ }^{[1]}$ yielded a grain growth exponent $\mathrm{n}$ of 2 , a rate constant $\mathrm{k}$ equal to $1110 \mathrm{~m}^{2} / \mathrm{s}$, and activation energy $\mathrm{Q}=312 \mathrm{~kJ} / \mathrm{mol}$ for the phenomenological grain growth relation, i.e.,

$$
\mathrm{D}^{\mathrm{n}}-\mathrm{D}_{\mathrm{o}}^{\mathrm{n}}=\mathrm{k}(\exp [-\mathrm{Q} / \mathrm{RT}])\left(\mathrm{t}-\mathrm{t}_{\mathrm{o}}\right),
$$

in which $\mathrm{D}=2 \mathrm{R}$.

To determine $\mathrm{M}$ from the measurements of Semiatin et al. ${ }^{[1]}$ the HAB-alone analog of Eq. [1] was written as the following:

$$
\frac{d D}{d t}=4 M \gamma\left(\frac{1}{D}\right)
$$

or in integrated form as

$$
D^{2}-D_{o}^{2}=8 M \gamma\left(t-t_{o}\right) .
$$

For $\gamma=1 \mathrm{~J} / \mathrm{m}^{2}$, a comparison of Eqs [3] and [4b] yields a mobility $M$ of

$$
\mathrm{M}\left(\mathrm{m}^{4} / \mathrm{Js}\right)=139 \exp (-37525 / \mathrm{T}(\mathrm{K})) .
$$

Model simulations based on Eq. [1] for the growth of the beta grains with HABs into a matrix of subgrains are shown in Figure 17. Two sets of simulations were done, one using the mobility derived from the data in Reference 1 (i.e., Eq. [5]) as well as another based on a mobility equal to one-half of this value. The simulations showed the expected linear behavior at long times. Model predictions based on Eq. [3] as well as experimental measurements of the average size of the grains are also shown in Figure 17. 
A comparison of the predicted and measured values revealed agreement which may be considered reasonable, especially in view of uncertainties in the input material properties. The results lie between the upper bound assumption, i.e., HABs growing into a population of subgrains, and classical curvature-controlled grain growth indicating that a combination of both mechanisms are operative. This is evident at longer annealing times after nucleated beta grains begin to impinge on one another (Figure 9(d)).

\section{IMPLICATIONS}

The present observations are also relevant to the formation of abnormally large beta grains during beta annealing of two-phase titanium alloys, which has been a longstanding issue in industry. The data shows that a grain highly misoriented with respect to a matrix comprised of LABs will grow into the matrix until it impinges on other highly misoriented grains and transition to a curvature-controlled growth process. Hence, slow heating rates into the beta phase field, such as those encountered during heating of large structural aerospace forgings, result in lower nucleation rates and would allow highly misoriented grains to grow to large sizes before encountering another high angle boundary. These results also suggest that a required precursor for abnormal grain growth in the beta phase field is the presence of a strong bcc texture comprised of a dominant component that is arranged into subgrains. Such a texture may be realized in deformation paths that approach plane-strain compression like rolling or side-pressing of a long cylinder. Hence, it is critical for billet converters and forging houses to work together to ensure that deformation is imparted in multiple directions in order to avoid forming a single, strong texture component. Such a team could use viscoplastic crystal plasticity analysis ${ }^{[38]}$ to determine the textures developed during billet conversion and then devise a forging schedule that does not further reinforce the texture in the billet.

The formation of abnormally large grains is detrimental to quasi-static properties, especially ductility, but more importantly fatigue and fracture properties. In the latter case, the presence of large prior beta grains containing large alpha colonies leads to significant microstructurally-influenced (i.e., rapid small crack growth effects) over physically large distances. This results in the formation of a physically large crack (on the order of $5 \mathrm{~mm}$, or larger) in a relatively small number of cycles and a corresponding larger driving force (e.g., stress intensity range) for continued growth when the crack enters the Paris, or long crack, regime. Collectively, these two effects can result in nonconservative designs if not taken into consideration.

\section{CONCLUSIONS}

The early stages of microstructure evolution during beta annealing of subtransus-hot-worked alpha/beta titanium alloys were characterized using a series of short time heat treatments of Ti-6Al-4V sheet. The following conclusions were drawn from this work:

1. The beta phase undergoes metadynamic recrystallization characterized by the growth of a population of pre-existing, highly-misoriented grains into a matrix of low-misorientation subgrains. For the Ti-6Al-4V sheet considered here, the majority of subgrains present above the beta-transus were characterized by a strong rotated-cube texture with a Gaussian distribution of orientations about the principal texture component. The pre-existing nuclei that gave rise to recrystallization were the minority grains in the tail of the Gaussian distribution and others that were highly misoriented with respect to the majority rotated-cube subgrains.

2. Recrystallization results in the elimination of the very strong, principal rotated-cube texture component, which is associated with the beta subgrain structure, and its replacement by a substantially-weaker texture comprising grains in the tail of the rotated cube texture, other rolling texture components, and random grains that collectively consume the original beta matrix.

3. The migration of the recrystallized grains may be estimated using a simple numerical model which indicates a linear rate of growth whose magnitude is a function of the product of the mobility of the high-angle boundaries and the surface energy and inverse size of the beta subgrains. In the present case, the estimated mobility was $139 \exp (-37525 /$ $\mathrm{T}(\mathrm{K})) \mathrm{m}^{4} / \mathrm{Js}$.

\section{ACKNOWLEDGMENTS}

This work was conducted as part of the in-house research of the Metals Branch of the Air Force Research Laboratory's Materials and Manufacturing Directorate. The authors thank K.T. Kinsel and P.N. Fagin for help in performing the experiments and Professor Tony Rollett (CMU) for many useful discussions. The program material was graciously supplied by RTI, Inc (Dr. Oscar $\mathrm{Yu}$ ). One of the authors (GAS) was supported under the auspices of Contract FA8650-10-D-5226.

\section{REFERENCES}

1. S.L. Semiatin, J.C. Soper, and I.M. Sukonnik: Acta Metall. Mater., 1996, vol. 44, pp. 1979-86.

2. S.P. Fox: in Titanium '92: Science and Technology, F.H. Froes and I.L. Caplan, eds., TMS, Warrendale, PA, 1992, pp. 769-76.

3. S.L. Semiatin, P.N. Fagin, M.G. Glavicic, I.M. Sukonnik, and O.M. Ivasishin: Mat. Sci. Eng. A, 2001, vol. A299, pp. 225-34.

4. O.M. Ivasishin, S.V. Shevchenko, and S.L. Semiatin: Mat. Sci. Eng. A, 2002, vol. A332, pp. 343-50.

5. O.M. Ivasishin, S.L. Semiatin, P.E. Markovsky, S.V. Shevchenko, and S.V. Ulshin: Mat. Sci. Eng. A, 2002, vol. A337, pp. 88-96.

6. O.M. Ivasishin, S.V. Shevchenko, P.E. Markovsky, and S.L. Semiatin: in Ti-2003: Science and Technology, G. Lütjering, and J. Albrecht, eds., Wiley, Weinheim, 2004, pp. 1307-14. 
7. G. Abbruzzese and K. Lücke: Acta. Metall., 1986, vol. 34, pp. $905-14$.

8. H. Eichelkraut, G. Abbruzzese, and K. Lücke: Acta Metall., 1988, vol. 36, pp. 55-68.

9. O.M. Ivasishin, S.V. Shevchenko, N.L. Vasiliev, and S.L. Semiatin: Acta Mater., 2003, vol. 51, pp. 1019-34.

10. N. Ma and Y. Wang: in Numiform 2004, S. Ghosh, J.M. Castro, and J.K. Lee, eds., American Institute of Physics, College Park, MD, 2004, pp. 1700-04.

11. N. Ma, A. Kazaryan, S.A. Dregia, and Y. Wang: Acta Mater., 2004, vol. 52, pp. 3869-79.

12. H. Moustahfid, N. Gey, M. Humbert, and M.J. Philippe: Metall. Mater. Trans. A, 1997, vol. 28A, pp. 51-61.

13. S.V. Divinski, V.N. Dnieprenko, and O.M. Ivasishin: Mat. Sci. Eng. A, 1998, vol. A243, pp. 201-05.

14. D. Bhattacharyya, G.B. Viswanathan, S.C. Vogel, D.J. Williams, V. Venkatesh, and H.L. Fraser: Acta Mater., 2006, vol. 54, pp. 231-36.

15. G.C. Obasi, R.J. Moat, D.G.L. Prakash, W. Kockelmann, J. Quinta da Fonseca, and M. Preuss: Acta Mater., 2012, vol. 60, pp. 7169-82.

16. A.P. Woodfield, M.D. Gorman, R.R. Corderman, J.A. Sutliff, and B. Yamrom: in Titanium '95: Science and Technology, P.A. Blenkinsop, W.J. Evans, and H.M. Flower, eds., Institute of Materials, London, 1995, pp. 1116-1123.

17. T.R. Bieler and S.L. Semiatin: Int. J. Plast., 2002, vol. 18 , pp. $1165-89$.

18. N. Gey, P. Bocher, E. Uta, L. Germain, and M. Humbert: Acta Mater., 2012, vol. 60, pp. 2647-55.

19. S.L. Semiatin, K.T. Kinsel, A.L. Pilchak, and G.A. Sargent: $M e-$ tall. Mater. Trans. A, 2013, vol. 44A, pp. 3852-65.

20. A.R. Shiveley, P.A. Shade, A.L. Pilchak, J.S. Tiley, and R. Kerns: J. Microsc., 2011, vol. 244, pp. 181-86.
21. A.L. Pilchak, A.R. Shively, J.S. Tiley, and D.L. Ballard: $J$. Microsc., 2011, vol. 244, pp. 38-44.

22. M. Humbert, H. Moustahfid, F. Wagner, and M.J. Philippe: Mater. Sci. Forum, 1994, vol. A157, pp. 1225-30.

23. M. Humbert, F. Wagner, H. Moustahfid, and C. Esling: J. Appl. Cryst., 1995, vol. 28, pp. 571-76.

24. M.G. Glavicic, P.A. Kobryn, T.R. Bieler, and S.L. Semiatin: Mater. Sci. Eng. A, 2003, vol. A346, pp. 50-59.

25. M.G. Glavicic, P.A. Kobryn, T.R. Bieler, and S.L. Semiatin: Mater. Sci. Eng. A, 2003, vol. A351, pp. 258-64.

26. A.L. Pilchak and J.C. Williams: Metall. Mater. Trans. A, 2011, vol. 42A, pp. 773-794.

27. C. Cayron: Acta Cryst A, 2006, vol. A62, pp. 21-40.

28. S.L. Semiatin, S.L. Knisley, P.N. Fagin, F. Zhang, and D.R. Barker: Metall. Mater. Trans. A, 2003, vol. 34A, pp. 2377-86.

29. C.M. Sellars: in Thermec 88. vol. 2, I. Tamura, ed., Iron Steel Institute of Japan, Tokyo, 1988, pp. 448-57.

30. J.J. Jonas: in Proc. 4th Int. Conf. Strength Metals Alloys., Laboratoire de Phsysique du Solide, E.N.S.M.I.M., I.N.P.L., Nancy, France, 1976, pp. 976-1002

31. G. Shen, S.L. Semiatin, and R. Shivpuri: Metall. Mater. Trans. A, 1995, vol. 26A, pp. 1795-1803.

32. M. Avrami: J. Chem. Phys., 1940, vol. 8, pp. 212-24.

33. J.E. Burke and D. Turnbull: Prog. Metal Phys., 1952, vol. 3, pp. 220-92.

34. J.W. Cahn: Acta Metall., 1956, vol. 4, pp. 449-59.

35. F.J. Humphreys: Acta Mater., 1997, vol. 45, pp. 4231-40.

36. W.T. Read and W. Shockley: Phys. Rev., 1950, vol. 78, pp. 275-89.

37. A.D. Rollett and E.A. Holm: in Proc. ReX'96 3rd Int. Conf. Recryst. Relat. Phenom. T.R. McNelley, ed., Monterey Institute of Advanced Studies, Monterey, 1997, pp. 31.

38. R.A. Lebensohn and C.N. Tome: Acta Metal. Mater., 1993, vol. 41 (9), pp. 2611-24. 